\title{
IDENTIFICANDO A MATEMÁTICA NO CONTEXTO INDÍGENA: UMA EXPERIÊNCIA NO ENSINO SUPERIOR
}

\author{
IDENTIFYING MATHEMATICS IN THE INDIGENOUS CONTEXT: AN EXPERIENCE \\ IN HIGHER EDUCATION
}

\author{
IDENTIFICAR LAS MATEMÁTICAS EN EL CONTEXTO INDÍGENA: UNA \\ EXPERIENCIA EN LA EDUCACIÓN SUPERIOR
}

\section{Bruna Larissa Cecco $^{1}$}

\begin{abstract}
RESUMO
O presente relato é fruto de uma experiência numa turma especial de estudantes indígenas da Universidade Federal da Fronteira Sul campus Chapecó no segundo semestre de 2018. O texto trata de uma prática de sala de aula desenvolvida no componente curricular de Matemática Instrumental com o objetivo de identificar a presença da matemática na comunidade indígena através das vivências cotidianas, produção do artesanato, jogos, cosmologia, costumes e cultura. A atividade, na perspectiva da etnomatemática, consistiu na realização de um trabalho pelos estudantes, no qual deveriam pesquisar sobre os conhecimentos matemáticos inerentes à realidade, propiciando o desenvolvimento de aulas mais dinâmicas e produtivas. Ao final da experiência, avalia-se que o componente aproximou os estudantes da matemática formal e que os mesmos sentem-se valorizados ao perceber que o seu povo construiu uma matemática própria, utilizada em diferentes contextos.
\end{abstract}

PALAVRAS-CHAVE: Etnomatemática; Educação superior; Povos indígenas.

\section{ABSTRACT}

This report is the result of an experience in a special class of indigenous students of the Federal University of Fronteira Sul, Chapecó campus in the second semester of 2018. The text deals with a classroom practice developed in the Instrumental Mathematics curriculum component in order to identify the presence of mathematics in the indigenous community through daily experiences, handicraft production, games, cosmology, customs and culture. The activity, from the perspective of ethnomathematics, consisted in the accomplishment of a work by the students, in which they should research on the mathematical knowledge inherent to reality, providing the development of more dynamic and productive classes. At the end of the experiment, it is estimated that the component brought students closer to formal mathematics and that they feel valued when they realize that their people have built their own mathematics, used in different contexts.

KEYWORDS: Ethnomathematics. College education. Indian people.

\section{RESUMEN}

Este informe es el resultado de una experiencia en una clase especial de estudiantes indígenas del campus de la Universidad Federal de Fronteira Sul Chapecó en el segundo semestre de 2018. El texto trata de una práctica en el aula desarrollada en el componente del plan de estudios de Matemática Instrumental para identificar la

1 Mestra em Educação e licenciada em Matemática pela Universidade Comunitária de Chapecó (UNOCHAPECÓ). Professora efetiva no Instituto Federal Farroupilha - campus Alegrete.

\begin{tabular}{c|c|c|c}
\hline Rev. Ciências Humanas & Frederico Westphalen, RS & Pg. 182-192 & Maio/Agosto 2019 \\
\hline \multicolumn{2}{c}{ Recebido em: 31/08/2019 } & Aceito em: 09/05/2019 \\
\hline
\end{tabular}




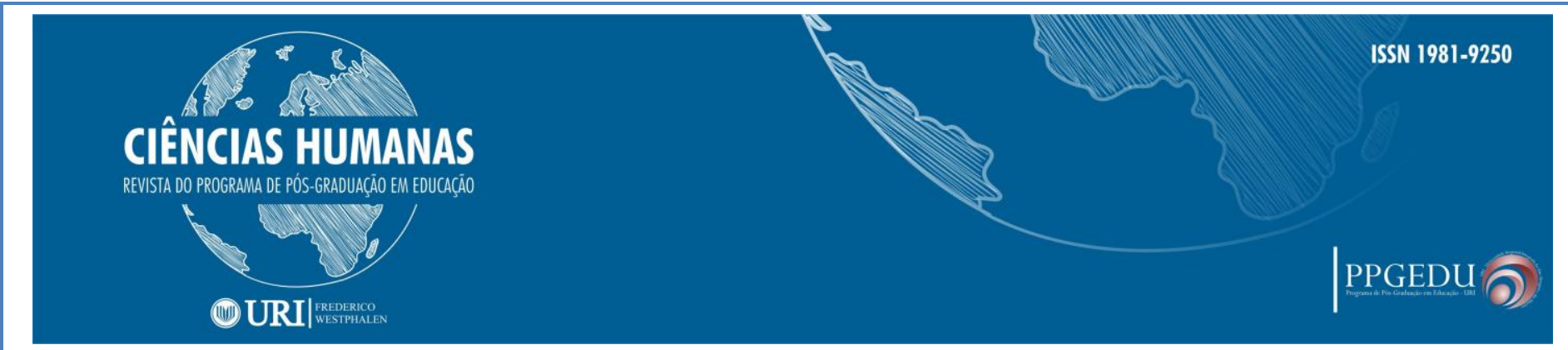

presencia de las matemáticas en la comunidad indígena a través de experiencias cotidianas, producción artesanal, juegos, cosmología, costumbres y cultura. La actividad, en la perspectiva de la etnomatemática, consistió en la realización de un trabajo por parte de los alumnos, en el que debían investigar sobre el conocimiento matemático inherente a la realidad, proporcionando el desarrollo de clases más dinámicas y productivas. Al final del experimento, se estima que el componente acercó a los estudiantes a las matemáticas formales y que se sienten valorados cuando se dan cuenta de que su gente ha construido sus propias matemáticas, utilizadas en diferentes contextos.

PALABRAS CLAVE: Etnomatemáticas. Educación universitária. Pueblos indígenas.

\section{CONSIDERAÇÕES INICIAIS}

O presente texto foi desenvolvido a partir de uma experiência realizada no componente curricular de Matemática Instrumental com uma turma especial de estudantes indígenas na Universidade Federal da Fronteira Sul (UFFS) - campus Chapecó. A instituição criou em 2013, um programa específico para os povos indígenas buscando promover a inclusão étnica e criar alternativas para o acesso e permanência dos mesmos na educação superior.

A universidade que abrange mais de 400 municípios do Sudoeste do Paraná, Oeste de Santa Catarina e Noroeste do Rio Grande do Sul, possui campus nas cidades de Chapecó (SC) - sede da Instituição, Realeza e Laranjeiras do Sul no estado do Paraná, e Cerro Largo, Erechim e Passo Fundo no Rio Grande do Sul. Diante da sua localização, a universidade tem no seu entorno várias Terras Indígenas ${ }^{2}$, como destaque: Aldeia Kondá (SC), Pinhal (SC), Toldo Chimbangue I e II (SC), Toldo Pinhal (SC), Xapecó (SC), Votouro (RS), Serrinha (RS), Nonoai (RS), Boa vista (PR), Palmas (PR), Mangueirinha (PR), entre outras.

Diante da sua inserção regional e compromisso social, a Instituição vem desenvolvendo cursos de graduação e pós-graduação atenta às demandas locais. Nesse sentido, é essencial que sejam pensadas estratégias observando as necessidades e especificidades dos diversos sujeitos envolvidos no ambiente universitário.

Com esse objetivo e o de valorização da cultura indígena foi proposto à turma um trabalho de pesquisa sobre a matemática inerente à realidade da comunidade indígena por meio da Etnomatemática. D’Ambrósio (2002) assume Etnomatemática como um programa,

\footnotetext{
${ }^{2}$ A maioria das Terras Indígenas localizadas nessa região são de etnia Kaingang ou Guarani. Para conhecer a lista completa das terras indígenas da região sul consultar o site da Fundação Nacional do Índio. Disponível em <http://www.funai.gov.br/index.php/indios-no-brasil/terras-indigenas>. Acesso em: 05 mai. 2019.

\begin{tabular}{c|c|c|c}
\hline Rev. Ciências Humanas & Frederico Westphalen, RS & Pg. 182-192 & Maio/Agosto 2019 \\
\hline Recebido em: 31/08/2019 & Aceito em: 09/05/2019 \\
\hline
\end{tabular}
}




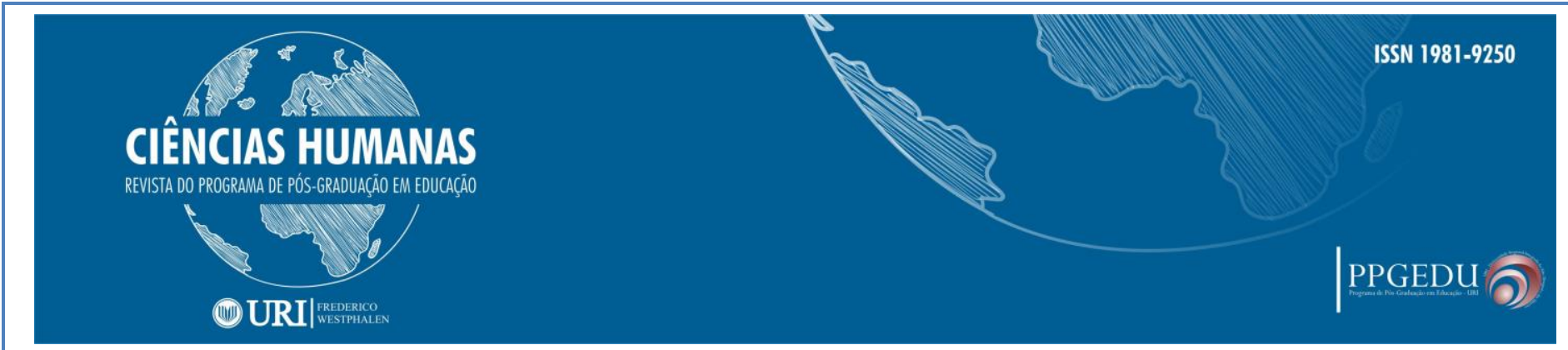

que surge de um inconformismo com a fragmentação do conhecimento. Dessa forma, ao enfatizarmos a aproximação existente entre a matemática utilizada pelo indígena e a matemática formal, começamos, mesmo que brevemente, a transpor essa "barreira" de uma matemática única e a superar a ideologia da certeza (BORBA; SKOVSMOSE, 2001).

\title{
Uma contextualização sobre o Programa
}

Em 2013, a Universidade Federal da Fronteira Sul instituiu o Programa de Acesso e Permanência dos Povos Indígenas (PIN) com o intuito de promover a inclusão social e étnica e buscar alternativas viáveis para o acesso e a permanência de indígenas na educação superior, bem como seu envolvimento nas atividades de ensino, pesquisa e extensão ${ }^{3}$.

Assim, através da Resolução $n^{\circ}$ 33/CONSUNI/2013 (UFFS, 2013b) alterada pela Resolução no 20/CONSUNI/2017 ficou instituído o Programa de Acesso e Permanência dos Povos Indígenas (PIN), o qual

\begin{abstract}
Art. $2^{\circ}[\ldots]$ constitui-se em instrumento de promoção dos valores democráticos, de respeito à diferença e à diversidade socioeconômica e étnico-racial, mediante a adoção de uma política de ampliação do acesso aos seus cursos de graduação e pósgraduação e de estímulo à cultura, ensino, pesquisa, extensão e permanência na Universidade. (UFFS, 2013b)
\end{abstract}

Com o principal objetivo de oportunizar o acesso aos cursos de graduação aos povos indígenas, o documento apresenta que o ingresso dos estudantes indígenas nos cursos de graduação poderá ocorrer de três formas distintas: via Enem/SiSU; mediante Processo Seletivo Exclusivo Indígena, com 2 (duas) vagas suplementares por curso, excetuando-se aqueles para os quais a Universidade não tem autonomia para ofertar vagas suplementares; e mediante Processo Seletivo Especial, para atender demandas específicas, por meio de aprovação de projeto pelo CONSUNI. (UFFS, 2013b)

Além das entradas regulares, a instituição possibilita que o ingresso da população indígena ocorra por um processo exclusivo, que geralmente acontece em meados de outubro ou novembro de cada ano. Não somente tocante ao acesso dos estudantes indígenas, o documento também expressa uma atenção em relação à permanência dos mesmos na

3 Retirado da página da UFFS, ingresso, processos seletivos especiais. Disponível em: <https://www.uffs.edu.br/institucional/pro-reitorias/graduacao/ingresso/processos-seletivosespeciais/programa_de_acesso_e_permanencia_dos_povos_indigenas>. Acesso em: 04 de mai. 2019.

\begin{tabular}{l|c|c|c} 
Rev. Ciências Humanas & Frederico Westphalen, RS & Pg. 182-192 & Maio/Agosto 2019
\end{tabular}

\begin{tabular}{l|l} 
Recebido em: 31/08/2019 & Aceito em: 09/05/2019
\end{tabular}




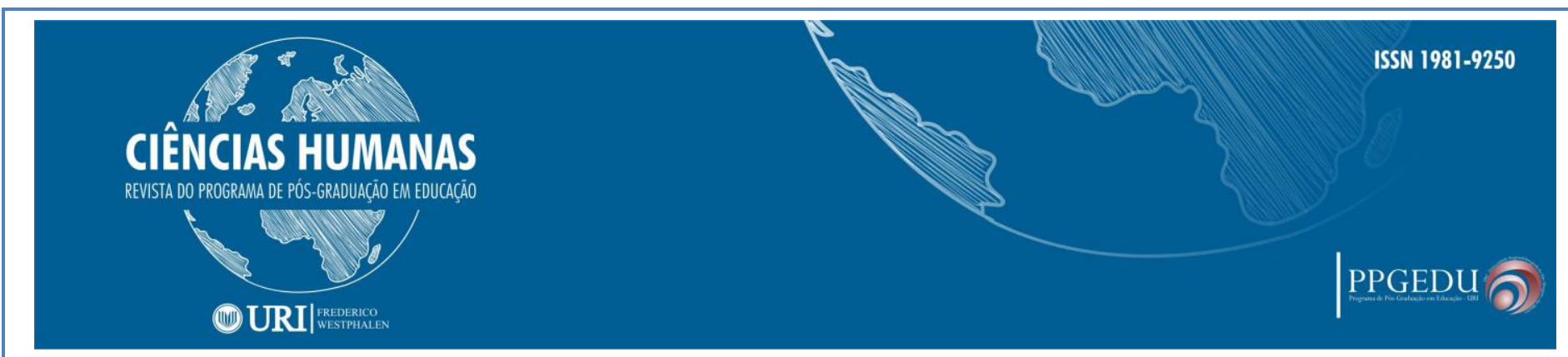

universidade. Sendo assim, o capítulo III da resolução (UFFS, 2013b) traz sete incisos em seu art. $9^{\circ}$ com ações visando à permanência dos mesmos, como por exemplo:

I - apoio acadêmico (monitoria/tutoria/acompanhamento psico-sociopedagógico) estruturado em programas e projetos voltados para conteúdos e habilidades necessárias ao desempenho acadêmico e para aspectos relacionados ao processo de aprendizagem;

II - atenção à formação político-social como acadêmico, mediante o uso de metodologias de interação que privilegiem o (re)conhecimento das suas características socioculturais e econômicas, a fim de ampliar o repertório políticocultural e estimular uma inserção protagonista na Universidade;

III - promoção da educação das relações étnico-raciais a estudantes, docentes e técnico-administrativos nos diferentes âmbitos da vida universitária, por meio de cursos de formação sócio-política e etnológica que permitam a percepção das diferenças culturais entre os diversos setores que comportam a Universidade, visando uma educação para a diferença, inclusive nos projetos pedagógicos; (UFFS, 2013b).

Pensando no aproveitamento acadêmico dos estudantes indígenas, a UFFS vem desenvolvendo um trabalho diferenciado. Através do PIN são oferecidas turmas especiais para indígenas com o objetivo de favorecer a permanência desse estudante por meio da vivência com seus pares e a adaptação no ambiente universitário. Essas turmas possibilitam que o mesmo seja inserido de forma gradativa no curso escolhido, propiciando que o mesmo possa ir se habituando na dinâmica do ensino superior. Assim, são oferecidos 4 (quatro) componentes curriculares por semestre no turno noturno e 1 (uma) noite de monitoria para estudo e esclarecimento de dúvidas. Em 2018/2, por exemplo, foram oferecidos como turma especial os componentes curriculares Matemática Instrumental, Estatística Básica, Direitos e Cidadania, e, Leitura e Produção Textual II, os quais pertencem ao Domínio Comum ${ }^{4}$.

O Domínio Comum, de acordo com o art. 12 da Resolução nº 4/2014 (UFFS, 2014), refere-se ao conjunto de componentes curriculares que são adotados por todos os cursos de graduação da UFFS, organizado em dois eixos de formação: contextualização acadêmica e formação crítico social. Visando uma formação cidadã e diante do grande número de estudantes oriundos de escola pública, o professor Darlan Trombeta aponta que "as disciplinas agrupadas no Domínio Comum pretendem oferecer uma formação básica, um suporte para o desenvolvimento de conteúdos básicos para ingresso na vida acadêmica.” (UFFS, 2013a).

\footnotetext{
${ }^{4}$ Os currículos dos cursos de graduação são constituídos de um "corpo de conhecimentos organizados em três domínios: Comum, Conexo e Específico, expressos na matriz em componentes curriculares e outras modalidades de organização do conhecimento". (UFFS, 2014)
}

\begin{tabular}{c|c|c|c}
\hline Rev. Ciências Humanas & Frederico Westphalen, RS & Pg. 182-192 & Maio/Agosto 2019 \\
\hline Recebido em: 31/08/2019 & Aceito em: 09/05/2019 \\
\hline
\end{tabular}




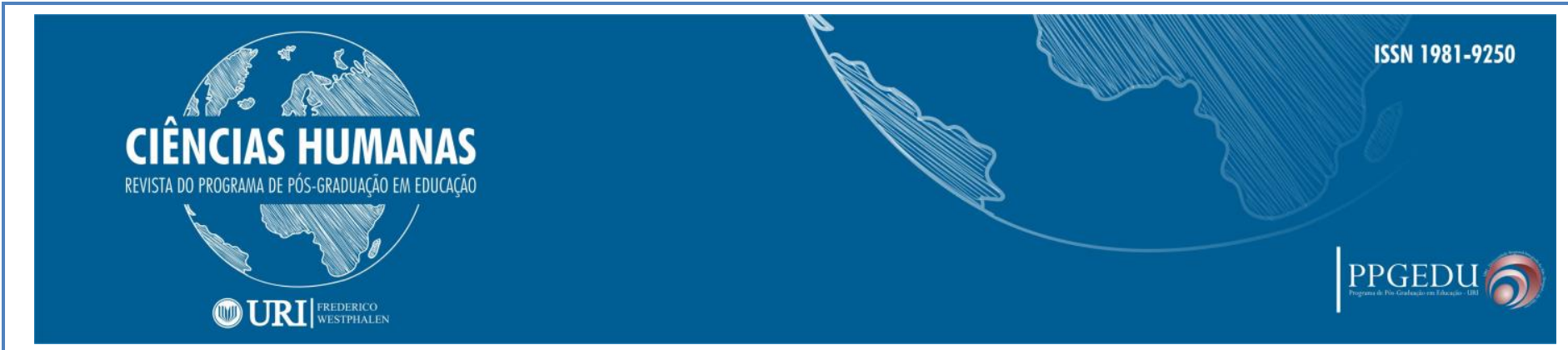

Matemática Instrumental é um dos componentes do eixo contextualização acadêmica, "com o objetivo de desenvolver habilidades e competências de leitura, de interpretação e de produção em diferentes linguagens que auxiliem a se inserir criticamente na esfera acadêmica e no contexto social e profissional." (UFFS, 2014). A linguagem matemática é uma importante ferramenta para leitura e compreensão do mundo e das relações, por isso sua importância em ser abordada através de um componente curricular que proporcione a evolução de noções matemáticas essenciais para análise e reflexão de problemas da realidade.

Diante da importância e ao mesmo tempo a dificuldade e aversão que os estudantes possuem em relação à Matemática e buscando evidenciar a sua presença no cenário indígena, entendeu-se que o componente deveria ser trabalhado de forma diferente como é usualmente, é a partir dessa organização que o relato se constrói.

\section{O desenvolvimento do componente curricular}

Em decisão conjunta, as aulas do componente curricular Matemática Instrumental aconteceram de forma concentrada nos meses de agosto e setembro, pois posteriormente os estudantes cursariam Estatística Básica. A ementa de Matemática Instrumental aponta noções de lógica e de conjuntos, relações, funções, trigonometria, matrizes e sistemas lineares, noções de matemática financeira, sistemas de medidas e geometria plana e espacial como conteúdos a serem trabalhados, os quais são estudados na educação básica.

Um dos objetivos específicos desse componente foi de "reconhecer/identificar a matemática inerente aos processos desenvolvidos no cotidiano, sobretudo no contexto da comunidade", visando assim proporcionar a aprendizagem de uma matemática que esteja mais "próxima" da realidade do estudante e "a atenção à formação político-social como acadêmico, mediante o uso de metodologias de interação que privilegiem o (re)conhecimento das suas características socioculturais e econômicas [...] e estimular uma inserção protagonista na Universidade.” (art. $9^{\circ}$ - inciso II, UFFS, 2013b).

A turma inicial era composta por 34 inscritos, porém 5 estudantes não compareceram em nenhuma aula. No primeiro encontro, com o objetivo de conhecê-los foi aplicado um questionário diagnóstico para compreender melhor quem eram os estudantes, a faixa etária, 


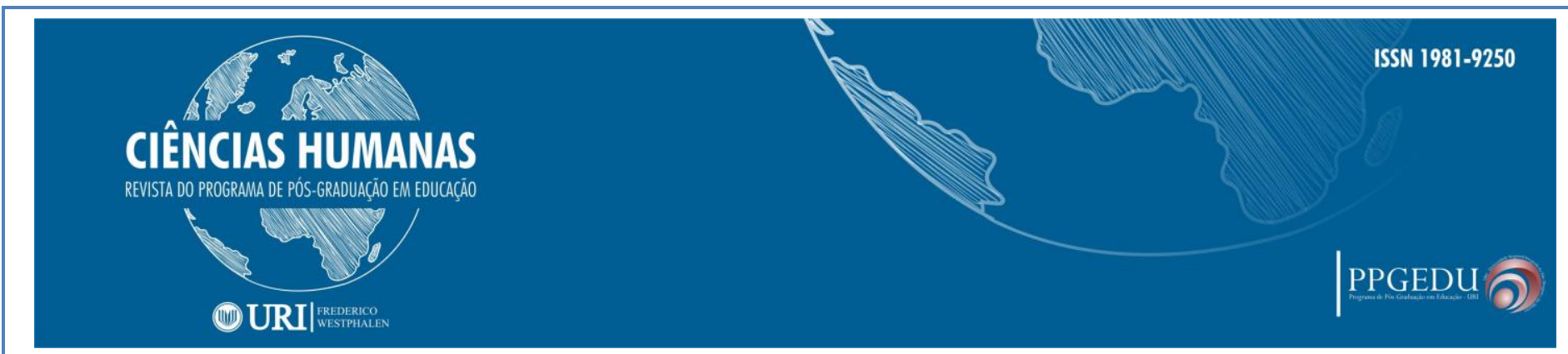

cidade de origem, número de filhos, trabalho, além de perguntar se os mesmos enxergavam a matemática na realidade, aonde e como.

Responderam ao questionário somente 22 estudantes, os quais são oriundos das aldeias Toldo Chimbangue (SC), Kondá (SC), Serrinha (RS), Pinhalzinho (RS), Votouro (RS) e Posto Indígena (sede) Nonoai (RS) que se deslocam para a universidade todos os dias, enquanto alguns moram em Chapecó. Dos diversos cursos oferecidos pela UFFS, os estudantes pertencem aos cursos de Ciência da Computação, Matemática, Filosofia, Engenharia Ambiental, Pedagogia, Ciências Sociais, Administração, Agronomia, Geografia e Letras.

Quanto às perguntas relacionadas à presença da matemática no contexto em que vivem e a sua utilização, as respostas foram bem diferentes, a maioria delas relacionando a matemática com o cotidiano de cada um, principalmente no âmbito do trabalho.

\footnotetext{
"Enxergo quando vou fazer compras e principalmente quando vou pagar as dívidas. E também, quando eu decido economizar".

"Sim, no ambiente onde eu trabalho. Quantidade de professores, ou seja, de funcionários que trabalham no local e o número de alunos, tamanho do pátio e das salas, da creche e quantidade de classes... Distância percorrida de casa para o trabalho, etc.".
}
"Sim, no meu trabalho, todo dia tem que contar quantas visitas faço, os relatórios no final do mês e também no artesanato a quantidade, a forma e o preço que cada um tem".
"Artesanato - figuras geométricas, extensão da área, número de pessoas, histórias ou lendas contadas pelos mais velhos das guerras vencidas, etc.".

"Sim, no orçamento do cliente para realizar o trabalho. Também ao iniciar um artesanato, ou seja, a quantidade de material necessário para a fabricação do mesmo".

Diante de algumas respostas selecionadas, é explícito que nem todos os estudantes conseguiam perceber a matemática intrínseca na cultura e realidade da sua coletividade, e aqueles que viam a matemática, no geral, conseguiam percebê-la apenas no artesanato.

Através de uma análise inicial surgiu a preocupação em realizar o ensino da matemática formal aproximando e valorizando os conceitos matemáticos inerentes ao cenário do povo indígena. Desta forma, a professora optou por desenvolver o componente curricular na perspectiva da etnomatemática, trazendo o estudante e suas vivências para o centro do processo de ensino aprendizagem.

\begin{tabular}{c|c|c|c}
\hline Rev. Ciências Humanas & Frederico Westphalen, RS & Pg. 182-192 & Maio/Agosto 2019 \\
\hline Recebido em: 31/08/2019 & Aceito em: 09/05/2019 \\
\hline
\end{tabular}




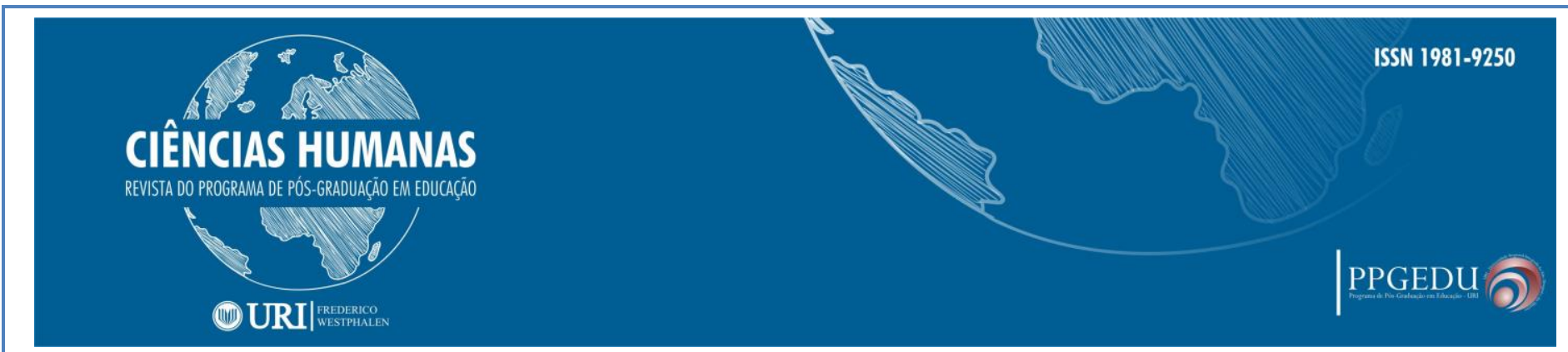

Como as autoras Knijnik, Wanderer, Giongo e Duarte (2012) enfatizam é importante "trazer a realidade" do aluno para a sala de aula, visto que a mesma possibilita dar significado aos conteúdos matemáticos, promovendo o interesse dos estudantes pela aprendizagem.

Essa foi a finalidade ao propor a atividade que será descrita a seguir, buscando perceber a presença de uma matemática não formalizada, mas que fora construída e utilizada pelos povos indígenas diante das necessidades sociais, aspectos inerentes à Etnomatemática, que na sua etimologia significa "a arte ou técnica (techné = tica) de explicar, de entender, de se desempenhar na realidade (matema), dentro de um contexto cultural próprio (etno)" (D’AMBROSIO, 2002, p. 10).

Assim, como uma avaliação do componente curricular, foi pensado no desenvolvimento de um trabalho que estava dividido em duas partes. Para a realização do mesmo, a turma foi separada em grupos com no máximo 4 integrantes, os quais deviam se articular levando em consideração o local onde moravam para facilitar na construção do trabalho.

A primeira parte teve como objetivo buscar, através da etnomatemática, compreender a presença da matemática na realidade da cultura/comunidade indígena. Para isso, algumas perguntas orientaram a construção do trabalho escrito que deveria ser entregue a professora, como por exemplo: De que comunidade fala? Localização, número de famílias... Como está organizada a comunidade? Qual é a rotina da comunidade? Como são divididas as famílias? Como é a organização familiar? Como são as construções, as casas?

Além disso, buscando reconhecer a matemática intrínseca na realidade: onde a matemática está presente na comunidade? Em quais processos ela aparece? Sugeria-se que os estudantes buscassem exemplos nos jogos e brincadeiras infantis, na cosmologia, no artesanato, nas construções, nas expressões artísticas, corporais e culturais, nos costumes (alimentação, venda/troca, finanças) e se fosse possível identificar a matemática que estava envolvida nesses processos.

Também foi destacado que os grupos entrevistassem pessoas mais velhas com o objetivo de entender como a comunidade utilizou(a) a matemática nos processos de sua organização. Para essa busca de dados foram sugeridos alguns questionamentos, como: Número: eles sempre existiram? Como era ou é a representação dos números? Medidas: 


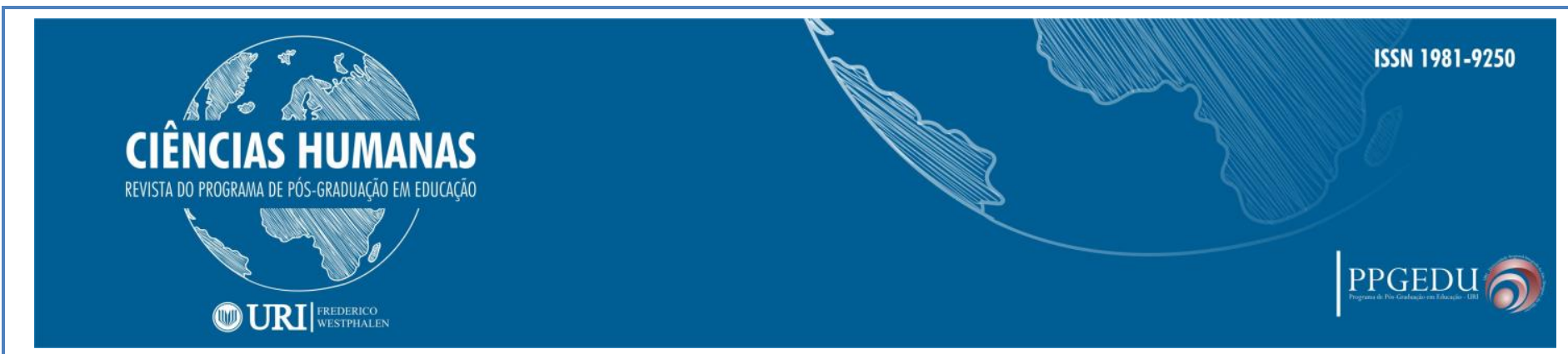

Como eram feitas as trocas de produtos? Quais medidas eram utilizadas (saca, palmo)?

Geometria: Como eram construídas as casas? Cálculos: Como se calculava na comunidade, utilizava-se calculadora?

A partir do encaminhamento os estudantes trouxeram diversas informações acerca da presença da matemática na sua realidade, sobretudo no desenvolvimento do artesanato, desde a obtenção dos materiais na mata até o processo de venda. Apesar de dificuldades na escrita e na organização textual, os estudantes elencaram conhecimentos importantes tanto em relação à vivência na comunidade quanto aos processos em que a matemática aparecia.

Após a entrega dos trabalhos pelos estudantes, a professora realizou a correção dos mesmos e identificou que a matemática tem presença importante nas relações cotidianas, na história, brincadeiras e costumes das comunidades indígenas. Com este conhecimento, a professora pode enriquecer as aulas ao trabalhar os conteúdos indicados na ementa do componente relacionando com a matemática inerente no contexto indígena.

Para a realização da segunda parte do trabalho, os grupos foram mantidos, pois a ideia era de que os mesmos se aprofundassem num tópico específico da matemática a partir do que foi abordado na $1^{\text {a }}$ parte do trabalho. Neste momento, os grupos deviam desenvolver uma parte escrita e também a apresentação. Para a organização e planejamento do mesmo foi destinada meia aula para que os estudantes pudessem organizar as ideias e esclarecer eventuais dúvidas com a professora, principalmente em relação à abordagem matemática, já que o objetivo desta parte é de formalizar os conceitos que foram salientados anteriormente no componente curricular.

Deste modo, os grupos trabalharam com os seguintes temas: Geometria presente no artesanato, estrutura e dimensão dos balaios, construção das casas de antigamente, pinturas corporais, grafismo e a questão da cosmologia, jogo da onça, jogo do buso, armadilhas (arapuca, entre outras) e o sistema de contagem.

Alguns dos temas que foram enfatizados pela turma já possuem escritos na literatura e são conhecidos, porém outros foram novidades tanto para a professora quanto para o restante da turma. É o caso, por exemplo, do jogo do buso, um jogo de sorte e que trabalha com contagem, a partir de milhos pintados ${ }^{5}$. Segundo o grupo que realizou a apresentação,

\footnotetext{
${ }^{5} \mathrm{O}$ jogo pode ser jogado em duplas e possui variações, mas de acordo com a apresentação feita, pode ter um \begin{tabular}{l|l|c|l}
\hline Rev. Ciências Humanas & Frederico Westphalen, RS & Pg. 182-192 & Maio/Agosto 2019
\end{tabular}

\begin{tabular}{l|l} 
Recebido em: 31/08/2019 & Aceito em: 09/05/2019
\end{tabular}
}




\section{CIÊNCIAS HUMANAS}

REVISTA DO PROGRAMA DE PÓS-GRADUAĞ̈O EM EDUCAĞ̄o

\section{(1) URI|}

este é um jogo muito antigo, conhecido pelos mais velhos, provavelmente uma brincadeira infantil.

Outro trabalho que chamou atenção da turma foi a respeito das casas ${ }^{6}$ que eram construídas com formato circular e enterradas, mantendo os moradores protegidos do frio. Os trabalhos que trataram dos artesanatos e da dimensão dos balaios também foram importantes, pois aproximaram os conceitos da matemática formal trabalhados no componente curricular com a realidade do povo indígena.

\section{CONSIDERAÇÕES FINAIS}

Ao propor um trabalho a ser realizado por estudantes que estão iniciando a vivência acadêmica percebe-se a dificuldade tanto em relação à escrita quanto ao desenvolvimento na apresentação. Além disso, muitos estudantes apontaram obstáculos para realizar a pesquisa na comunidade, pois precisaram conversar com pessoas mais velhas para obter o conhecimento, principalmente o grupo que pesquisou sobre o jogo do buso e o do sistema de numeração.

Nos relatos dos estudantes, percebe-se o quanto vão se afastando de alguns costumes e da cultura, e o quanto os conhecimentos e materiais não indígenas vão se incorporando nas vivências. Também ficou evidente nas apresentações a diferença existente no artesanato de duas comunidades (Kondá e Pinhalzinho) em relação à cor, formato e o trançado, mostrando a variedade existente nas diversas representações indígenas.

Nesse sentido, fica clara a necessidade e importância de existirem turmas especiais para indígenas, uma das ações do PIN, pois possibilita a interação e a troca de experiências entre um mesmo povo, porém de diferentes comunidades. Além disso, são oferecidas mais oportunidades aos estudantes indígenas do que quando estão inseridos em turmas regulares, pois geralmente são minoria e acabam tendo dificuldades para se expressar e se envolver com o restante da turma.

total de 47 ou 107 milhos, dos quais 7 devem ser pintados. O jogo consiste em separar os milhos pintados dos não pintados (banca). Cada jogador, na sua vez, lança os milhos pintados como se fossem dados, e recolhe a quantidade respectiva dos não pintados. O ganhador será quem tiver acumulado mais milhos não pintados e o jogo termina quando terminam os milhos.

Uma versão um pouco diferente foi encontrada em: <https://pnld2019.moderna.com.br/wpcontent/uploads/2018/06/157_final_BMCP_MD_LT3_MLRS02_G19.docx>. Acesso em: 09 mar. 2019.

${ }^{6}$ Para mais detalhes sobre as casas Kaingang, consultar: <http://multiplica.org/subterraneas-do-povo-kanghag/>. Acesso em: 25 abr. 2019.

\begin{tabular}{|l|c|c|c|} 
Rev. Ciências Humanas & Frederico Westphalen, RS & Pg. 182-192 & Maio/Agosto 2019
\end{tabular}




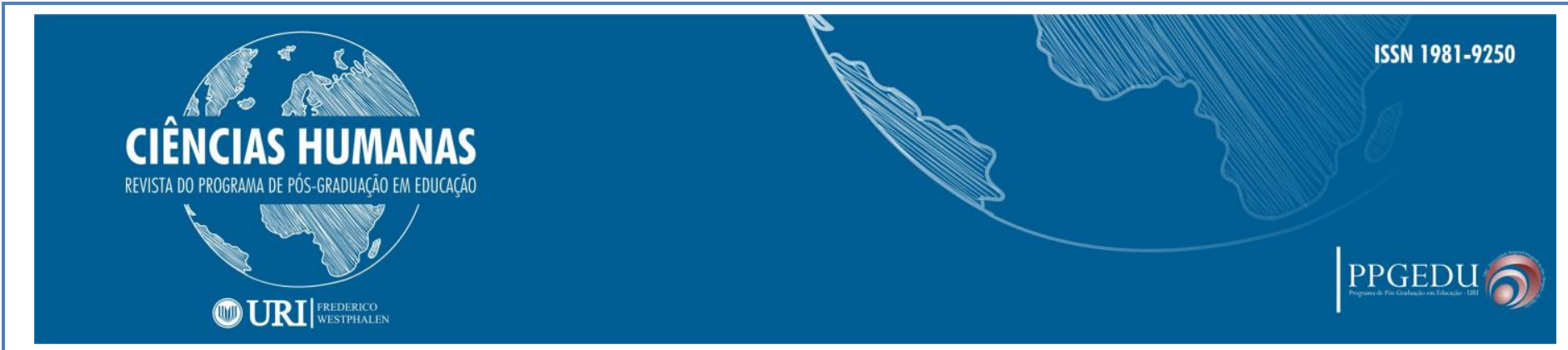

Numa avaliação final do componente, percebe-se o quanto que os estudantes sentemse valorizados ao perceber que o seu povo também se constituiu com uma matemática própria e que muitos deles ao desenvolverem artesanatos, mesmo que de forma inconsciente utilizam muita matemática nos seus afazeres, desde o processo de coleta de material até a finalização e venda do artesanato.

A atividade desenvolvida na turma com o reconhecimento do indígena e dos processos matemáticos presentes na sua realidade buscou mostrar a capacidade de "fazer" matemática por diferentes povos e a desmistificação de uma matemática única e verdadeira. Como elencado por Borba e Skovsmose (2001, p. 148):

uma maneira de desafiar a ideologia da certeza é mudar a prática da sala de aula pela introdução de uma paisagem de discussão de natureza caótica, em que a relatividade, os pontos de partida provisórios, os diferentes pontos de vista e a incerteza são valorizados.

Esses são pontos essenciais à uma mudança de visão sobre essa matemática vista como uma "linguagem de poder", "como um sistema perfeito, como pura, como uma ferramenta infalível se bem usada" (BORBA; SKOVSMOSE, 2001, p. 129). Ao mostrarmos a existência de uma matemática que não é única como na própria nomenclatura do sistema de numeração Kaingang ou na produção do artesantato ou ainda na construção de armadilhas iniciamos um processo de superação da ideologia da certeza, mesmo que vagarosamente.

Afinal, como enfatizado por D'Ambrosio (2002, p. 11) para se levar a Etnomatemática às suas amplas possibilidades de pesquisa e de ação pedagógica é essencial liberar-se do padrão eurocêntrico e "procurar entender dentro do próprio contexto cultural do indivíduo, seus processos de pensamento e seus modos de explicar, entender e de se desempenhar na sua realidade". Esse foi um dos própositos do trabalho realizado e do componente curricular como um todo, buscando promover uma apreensão acerca do contexto indígena e da matemática inerente à essa realidade, evidenciando o seu valor e a sua importância tanto para o meio acadêmico quanto para o social. 


\section{REFERÊNCIAS}

BORBA, Marcelo; SKOVSMOSE, Ole. A ideologia da certeza em matemática. In: SKOVSMOSE, Ole. A educação matemática crítica: a questão da democracia. Campinas, SP: Papirus, 2001. (Coleção Perspectivas em Educação Matemática).

CASAS SUBTERRÂNEAS DO POVO KAINGANG. Disponível em <http://multiplica.org/subterraneas-do-povo-kanghag/>. Acesso em: 25 abr. 2019.

D'AMBROSIO, Ubiratan. Etnomatemática: um programa. Educação Matemática em Revista (SBEM), n.1, reedição, ano 8, julho, 2002.

FUNDAÇÃO NACIONAL DO ÍNDIO. Disponível em <http://www.funai.gov.br/inde x.php/indios-no-brasil/terras-indigenas >. Acesso em: 05 mai. 2019.

KNIJNIK, Gelsa; WANDERER, Fernanda; GIONGO, Ieda M.; DUARTE, Claudia G. Etnomatemática em movimento. Belo Horizonte: Autêntica Editora, 2012. (Coleção Tendências em Educação Matemática).

UFFS cria fóruns de disciplinas do Domínio Comum e Domínio Conexo. Chapecó, 5 dez. 2013a. Disponível em: <https://www.uffs.edu.br/institucional/reitoria/diretoria_de_ comunicacao/noticias/uffs-cria-foruns-de-disciplinas-do-dominio-comum-e-dominioconexo>. Acesso em: 02 mar. 2019.

UNIVERSIDADE FEDERAL DA FRONTEIRA SUL (UFFS). Conselho Universitário. Resolução no 33/2013 - CONSUNI, de 12 de dezembro de 2013, alterada pela resolução no 20 /CONSUNI/UFFS/2017, de 6 de dezembro de 2017. Institui o Programa de Acesso e Permanência dos Povos Indígenas (PIN) da Universidade Federal da Fronteira Sul, 2013b.

UNIVERSIDADE FEDERAL DA FRONTEIRA SUL (UFFS). Conselho Universitário, Câmara de graduação. Resolução n ${ }^{0}$ 4/2014 - CONSUNI/CGRAD, alterada pela resolução $n^{\circ}$ 9/CONSUNI/CGAE/UFFS/2018, de 13 de novembro de 2018. Aprova o Regulamento da Graduação da Universidade Federal da Fronteira Sul, 2014. 